\title{
O mundo do trabalho em xeque: o Brasil assolado pela insegurança jurídica da reforma trabalhista
}

Elisabeth Baraúna'

Aline Lourenço²

Ana Lole ${ }^{3}$

Inez Stampa ${ }^{4}$

\begin{abstract}
Resumo
$\mathrm{O}$ artigo analisa os efeitos das modificações legislativas trabalhistas no Brasil, no período de 2016 a 2020, observando a reforma trabalhista associada à terceirização e seus impactos nas relações de trabalho. Utiliza como metodologia a revisão bibliográfica e a análise documental. Considera que a regulação da terceirização impulsiona o aumento da precarização das condições de trabalho e de vida da população. Busca examinar as perspectivas do mundo do trabalho diante de tamanha austeridade e insegurança para a classe trabalhadora. Conclui que os retrocessos revelam uma agenda de desmonte de direitos e precarização massiva do trabalho no Brasil, incluindo a Justiça do Trabalho.
\end{abstract}

Palavras-chave

Trabalho; Neoliberalismo; Terceirização; Reforma trabalhista; Precarização.

The world of work in check: Brazil plagued by the legal uncertainty of labor reform

\begin{abstract}
The article analyzes the effects of Brazilian labor legislative changes in the period from 2016 to 2020, observing the labor reform in the context of outsourcing and its impacts on labor relations. It uses bibliographic review and document analysis as methodology. It considers that the regulation of outsourcing drives the increase in the precariousness of the working and living conditions of the population. It seeks to examine the perspectives of the world of work and the working class in face of such austerity and insecurity measures. It concludes that these setbacks reveal an agenda that aims for the dismantling of rights and to promote massive precariousness of work in Brazil.
\end{abstract}

\section{Keywords}

Work; Neoliberalism; Outsourcing; Labor reform; Precariousness. 
Artigo recebido em junho 2020

Artigo aprovado em agosto de 2020

\section{Introdução}

O artigo analisa os efeitos das modificações legislativas nos últimos anos, no Brasil, no período do governo Temer até a atualidade (20162020) ${ }^{5}$, observando-se a reforma trabalhista, agregada à terceirização e seus impactos nas relações de trabalho no país, com base no pressuposto de que a terceirização tem funcionado como um mecanismo de degradação do trabalho e que a sua regulação - incorporada pela Lei $n^{\circ} 13.429 / 2017^{6}$, denominada Lei da Terceirização - impulsiona o aumento da precarização do trabalho, funcionando como estímulo à ampliação de condições que são favoráveis apenas à classe patronal. Isso resulta no aumento do desmonte dos direitos do trabalho, visto que a desregulamentação das relações trabalhistas se traduz em dispositivos jurídicos que ampliam a flexibilização ${ }^{7}$ e acentuam elementos que rompem com princípios já frágeis, mas antes assegurados pela Consolidação das Leis do Trabalho (CLT).

A relação capital-trabalho, pela sua natureza, é produtora de precarização das condições de trabalho e de reprodução da classe trabalhadora. No intuito de obter aumento da mais-valia, utiliza a terceirização como elemento decisivo para a flexibilização das relações de trabalho, alimentando os anseios da classe patronal no tocante aos altos lucros, taxas de produtividade, redução de custos, volatilidade nas formas de contrato e inserção no mercado, assim como quanto à questão de pressão pela maximização do tempo no exercício das funções, tudo para corroborar, diuturnamente, a força de trabalho como mercadoria (ANTUNES, 2018).

No contexto da agenda econômica neoliberal, merece destaque a temática da pressão pelo tempo na atividade laboral por ocasião de implantação de políticas austeras, onde a virtualização da vida 
mantém em constante ocupação o trabalhador contemporâneo. A flexibilização do trabalho se espelha em diversos âmbitos, principalmente no que diz respeito ao tempo (DAL ROSSO, 2017).

O que se pode constatar, de imediato, é que, com esses atributos, a reforma trabalhista, aliada à terceirização, assume centralidade na estratégia patronal, onde as políticas de gestão empresarial se transformam sob a chancela legislativa, desprezando a vulnerabilidade histórica e estrutural da classe trabalhadora, enfatizando a liberdade e a autonomia da vontade do trabalhador frente à relação de emprego, instrumentos livres para a obtenção e crescimento industrial e para lucros incessantes, inspirados no toyotismo e na acumulação flexível.

Neste sentido, o presente artigo se propõe analisar os efeitos das alterações normativas do trabalho no Brasil atual, em especial a reforma trabalhista agregada à terceirização, examinando seus impactos nas relações de trabalho no Brasil.

\section{Crise do capital e as relações de trabalho no Brasil}

$\mathrm{Na}$ conjuntura de um novo ciclo de reestruturação do modo de produção capitalista, foram produzidas mudanças que impactaram fortemente as relações de trabalho no Brasil.

As crises cíclicas do capitalismo fazem parte de seu próprio processo de expansão e recuperação, trazendo transformações importantes ao mundo do trabalho, seja nas formas de organização como, também, nas relações de trabalho. Com a crise encadeada na década de 1970, iniciou um processo de reorganização produtiva aliada à implementação de políticas de cunho neoliberal com privatizações, redução do investimento na área social, bem como alteração do processo produtivo e do mercado de trabalho. Essas ações fazem parte do conjunto de financeirização e mundialização da economia capitalista. Tal contexto é fundamental para compreendermos o processo de rompimento com o padrão fordista, caracterizado por um período de trabalho majorita- 
riamente contratado e regulamentado, em especial em países centrais e que vem sendo substituído por um modo de trabalho e de vida da classe trabalhadora pautado na flexibilização e na precarização da força de trabalho (ANTUNES; DRUCK, 2015).

A produção "flexível" e "enxuta" faz parte desse novo modo de organização do trabalho e cria empresas e formas de contrato de trabaIho diferentes das garantias legais que vigoraram no século XX (MARCELINO; CAVALCANTE, 2012). Trazem em seu bojo novas formas de organização do trabalho, com o intuito de reposição e aumento da taxa de lucro, acirrando a exploração da classe trabalhadora, já que a lógica da acumulação passa pelas formas precarizadas de trabalho, tais como: o trabalho temporário, terceirizado, informal.

Cumpre destacar a ofensiva neoliberal ocorrida no Brasil a partir da década de 1990, bem como nuances do reflexo mundial da crise americana de 2008, visto que é nesse período que as formas de organização do trabalho no Brasil passam a ter como base processos de aperfeiçoamento de gestão do trabalho, conforme indicam os estudos de Harvey (2016) e Antunes (2018). Importante enfatizar que esta análise tem como apoio fundamental o entendimento de que as recentes transformações são efetuadas como base do processo de continuidade da estratégia neoliberal. Para tanto, são examinadas à luz da Teoria Marxista da Dependência (MARINI, 2011).

De modo bastante objetivo, compreende-se que a situação atual do país se dá em função da lógica da economia mundial, com aumento da dependência financeira e intensificação da subordinação aos países centrais, dentro da divisão internacional do trabalho, ou seja, o "subdesenvolvimento" dos países pobres como condição necessária para o "desenvolvimento" dos países ricos.

Torna-se premissa básica para a análise da conjuntura atual brasileira as asseverações de Galeano (1981), onde o método marxiano é o mais adequado para se apreender a dinâmica de funcionamento da sociedade em que vivemos. 
No presente artigo compreendemos que a Teoria Marxista da Dependência ocupa lugar importante dentro do debate teórico acerca das possíveis justificativas e procedências das mutações encontradas em nosso país recentemente, ponderando que "desenvolvimento" e "subdesenvolvimento" é um par dialético no processo da lógica instaurada.

Carcanholo (2004) afirma que a lógica da acumulação do capital em escala mundial subordina países periféricos aos países centrais, criando, assim, uma relação de dependência, refletindo a principal peculiaridade dessas economias: transferência de valor e superexploração da força de trabalho.

Então, pensar sobre a noção do padrão de reprodução do capital é pensar nas mediações teóricas capazes de capturar o movimento do capital em graus abstratos e concretos, pelas quais as leis de tendências do capitalismo vão se especificando e, também, onde temas como imperialismo, divisão internacional do trabalho, formação econômico-social e conjunturas, ancoradas na teoria do valor de Marx (2004), propõem como solução a condição de subdesenvolvimento austero.

A proliferação de insatisfação e intensificação daquilo que se propaga como crise pode ser definida, também, como instrumento do capital, visto que o mesmo tem seu ciclo e a política econômica é a ferramenta principal de acesso a seus ideários principais. No atual contexto, a retomada mais radical do projeto neoliberal, como defendeu o Consenso de Washington (HARVEY, 2016).

Desde então a economia brasileira se rendeu ao processo de globalização neoliberal através desse receituário e, na divisão internacional do trabalho, é um produtor de commodities. Para tanto, se fez necessário o conjunto de posturas que observamos ultimamente. Nota-se claramente que as economias dependentes, de certa forma, são forçadas a transferir parte da mais valia produzida internamente quando colocadas em concorrência com os capitais de quem tem a produtividade mais alta (MARINI, 2011). 
Novamente reportamo-nos a Carcanholo (2004), que explicita e identifica os condicionantes estruturais desta dependência, quais sejam, a transferência de valor através de juros, dividendos, amortizações, lucros e royalties derivados da importação de capital feita pelos países dependentes e a instabilidade dos mercados financeiros internos sob alta taxa de juros à mercê da liquidez internacional, ficando o capitalismo financeiro como o principal padrão de reprodução do capital.

Como consequência, a conjuntura brasileira atual é de consolidação de um projeto político que ataca diretamente a regulamentação do trabalho e a organização da classe trabalhadora. A reforma trabalhista, a regulamentação da terceirização das atividades fim e a extinção do Ministério do Trabalho, transformado em secretaria subordinada ao Ministério da Economia, são marcos importantes para entender a racionalização do Estado sob a ótica das mudanças impostas pelo capitalismo.

Somadas às grandes desigualdades no acesso à proteção social , essas mudanças trouxeram a desregulamentação dos direitos trabaIhistas básicos, garantidos pela luta da classe trabalhadora e afetou diretamente as formas de organização dos trabalhadores. A organização do trabalho é marcada por uma explosão da precariedade, da flexibilidade e da desregulamentação, onde os trabalhadores se transformam em reféns das péssimas condições de trabalho e dos baixos salários (JORDÃO; STAMPA, 2015).

Assim, na prática, foram impostas relações de trabalho que retiram direitos, diminuem salários, trabalhadores mais expostos a acidentes de trabalho e enfraquecidos em sua organização sindical, assumindo a terceirização "[...] cada vez mais relevo, tanto no processo de corrosão do trabalho e de seus direitos como incremento e na expansão de novas formas de trabalho produtivo gerador de valor" (ANTUNES, 2018, p. 32).

Segundo Gimenez e Krein (2016), o avanço da terceirização acentua o caráter desorganizado do mercado brasileiro, ao comportar várias 
modalidades de contratação que beneficiam as empresas ao dar liberdade na gestão da força de trabalho de acordo com sua demanda, o que, na verdade, submete os trabalhadores a condições de insegurança e instabilidade no trabalho.

Essas novas formas de trabalho estão diretamente vinculadas ao crescimento do setor de serviços e o uso de maquinário tecnológico-científico-informacional, que possibilita a intensificação da produtividade e coloca os trabalhadores em jornadas já determinadas, flexíveis e sem local de trabalho fixo, além de baixa remuneração. Uma expansão do capitalismo informacional e digital que, segundo Antunes (2018, p. 37), "podemos denominar uberização do trabalho".

A uberização ${ }^{9}$ faz parte das mudanças no mundo do trabalho, com uso de novas tecnologias, criando um conjunto de novos modelos de contrato de trabalho, onde grandes empresas detentoras dos aplicativos vendem a ideia de autonomia e empreendedorismo para "colaboradores"/autônomos/prestadores de serviço que, na verdade, são trabalhadores, que são responsabilizados pelos custos e riscos do trabalho. É criada uma falsa ideia de autogestão do seu tempo de trabalho e salário, trazendo o trabalhador para a ilusão ser um empreendedor ao trabalhar para uma empresa via aplicativo. É própria do capitalismo a criação de narrativas que mascaram a real natureza das relações de trabalho, o que é especialmente utilizado por essas empresas de aplicativos (ANTUNES; FILGUEIRAS, 2020).

Esses trabalhadores intermitentes recebem por hora trabalhada, sem nenhum vínculo empregatício com os proprietários das plataformas digitais. As relações são estabelecidas sem nenhuma regulamentação e com subcontratação e terceirização do trabalho, sendo o único "vínculo" o uso do aplicativo.

Para Antunes e Filgueiras (2020) a organização do trabalho vinculada ao uso das tecnologias e plataformas digitais são estratégias de contratação da força de trabalho que escondem o assalariamento, pois sua negação cria a ideia de autonomia para o trabalhador, ao 
mesmo tempo que aumenta sua exploração. A relação criada entre a empresa com o trabalhador, via aplicativo, retira a relação empregador e empregado e, simultaneamente, subordinando a relação. Somado a isto, há uma relação contraditória, onde a tecnologia possibilita "a identifıcação e a efetivação de direitos aos trabalhadores/as mais fácil do que em qualquer outro período da história. Contudo, com o discurso de que estamos diante de novas formas de trabalho que não estão sujeitas à regulação projetiva" (ANTUNES; FILGUEIRAS, 2020, p 29).

\section{Insegurança jurídica para a classe trabalhadora}

Reportamo-nos como reforma trabalhista à Lei n ${ }^{\circ} 13.467 / 2017^{10}$ que dispõe sobre volumosas alterações na Consolidação das Leis TrabaIhistas (CLT), com mais de 100 artigos modificados, que dão novo tônus ao mundo do trabalho.

Nessa conjuntura, observa-se que a reforma trabalhista e as leis pertinentes começaram timidamente, como um projeto de poucos artigos, e se transformou numa grande mudança não só da legislação trabalhista, mas, também, da estrutura do direito do trabalho, seus princípios e fundamentos. A Lei $n^{\circ} 13.467 / 2017$ prioriza a norma menos favorável ao empregado, a aparente livre autonomia da vontade através do negociado sobre o legislado, individual e coletivamente, valorizando a imprevisibilidade do trabalho intermitente em nome da liberdade do ajuste e ampliando pontos desfavoráveis ao trabalhador.

Ressalta-se, ainda, nesse aspecto, que, antes mesmo de ser aprovada a reforma trabalhista, foi sancionada a Lei $n^{\circ} 13.429 / 2017$, a Lei da Terceirização, a qual possibilita que as empresas possam contratar trabalhadores terceirizados para exercer cargos nas atividades-fım, que são aquelas ligadas às funções principais da empresa. Anterior a isso, a Justiça do Trabalho havia determinado que apenas fosse permitida a terceirização de atividades-meio, que são os serviços indispensáveis na empresa, mas que não possuem relação direta com a sua atividade principal. Considerando que está em curso uma 
série de modificações na legislação do trabalho e na previdência"1, $\overline{\bigcup_{2}}$ observa-se que essas têm sido direcionadas pela classe patronal a fim de garantir que as empresas possam reduzir custos, atracadas na flexibilização das leis trabalhistas.

As discussões sobre os aspectos materiais e processuais sobre a temática e suas consequências sociais costumam ser cautelosas no meio jurídico, uma vez que a essência das referidas leis desconstruíram diversos institutos consolidados pela legislação trabalhista brasileira. Como exemplo podemos citar, no âmbito do Tribunal Superior do Trabalho (TST), a edição da Instrução Normativa $n^{\circ} 41 / 2018^{12}$, oriunda da Resolução $n^{\circ} 221 / 2018^{13}$, no que tange a aplicabilidade das modificações e seu aspecto temporal.

Nessa seara, cumpre ressaltar que as modificações legislativas, para as quais nos atentamos no presente estudo, não foram devidamente compreendidas nem pelos tribunais superiores, significando dizer que, deste modo, não se alcança com tais normas a função plasmada na Constituição Federal de 1988 - a de manter segurança e estabilidade jurídica, sendo essa lacuna ponto importante e que precisa de solução para a sociedade em geral.

Depreende-se, então, como elemento de análise, a forma em que peculiaridades da reforma trabalhista, sobretudo no governo Temer, relacionadas principalmente com a terceirização do trabalho, se estruturam no Brasil e se ampliam frente à redefinição alicerçada por uma agenda neoliberal, que resultou na aprovação das leis em comento.

Desse modo, carecem de maior visibilidade as mudanças que estão sendo operadas nas relações de trabalho no Brasil, frente às novas configurações projetadas no país pela reforma trabalhista em andamento.

Encaminha-se, no Brasil, um projeto denominado de modernização da legislação trabalhista, que não indica possibilidade de diálogo com a classe trabalhadora, contrastando, nesse sentido, com as suas reais necessidades, bem como instituindo mudanças radicais que colocam em risco direitos conquistados arduamente pelos trabalha- 
dores. No âmbito da terceirização do trabalho, por exemplo, essas alterações apontam para enormes perdas.

Diante desses aspectos e do desmonte dos direitos do trabaIho que está sendo processado na agenda pública, dispositivos da reforma trabalhista e da terceirização se instauram em meio a um cenário de contrarreformas (BEHRING, 2003) e se apresenta como um elemento de forte tendência de aprofundamento da precarização do trabalho e da desregulamentação de direitos, tendo em vista que o aniquilamento de direitos do trabalho vem se dando, sobremaneira, via terceirização.

A relevância social e política da questão encontra razão no fato de que a motivação da modernização do trabalho não se concretiza mesmo após dois anos das transformações implementadas, haja vista que o que se pode avaliar a respeito do desmonte ocorrido é a intensificação, sem precedentes, de um desemprego avassalador no país, onde o que mais se propaga é polêmica e pobreza.

As feições relevantes do tema encontram razões plausíveis, considerando que, por princípio, a matriz básica do direito e legislações compostas para o trabalho devem estar centradas na proteção ao trabalhador, através do princípio da norma mais favorável e condição mais benéfica à classe trabalhadora.

Por essa razão, compreende-se que se a intenção de legislar era a de angariar melhoria de condições sociais aos trabalhadores, restou inócua a tentativa, uma vez que a reforma toma aparência de contrarreforma, simbolizando verdadeiro retrocesso de direitos.

No que se refere à dinâmica da construção das leis que alteram o mundo do trabalho, nesse recorte temporal que vai do governo de Temer aos dias atuais, notadas a Reforma Trabalhista e a Lei da Terceirização, é importante traçar o trajeto da sua regulação a partir de alguns marcos normativos, tais como: a Súmula $n^{\circ} 331$, do TST ${ }^{14}$; o Projeto de Lei $n^{\circ} 4.330 / 2004$; o Projeto de Lei $n^{\circ} 4.302 / 1998^{15}$ e, por fim, a Lei $n^{\circ}$ 13.429/2017 e a Lei $n^{\circ} 13.469 / 2017$. 
A reforma trabalhista brasileira está inserida em um contexto mundial de reformas neoliberais que trazem a flexibilização e o colapso do direito ao trabalho, o que também é observado em outros países, apesar de suas especificidades, porém, com pontos comuns no que diz respeito à desconstrução da proteção social, retrocesso nas relações e proteção do trabalho e com a pauta de negociação entre patrões e trabalhadores (DRUCK, 2019). Essa "reforma" se configura, segundo Druck (2019, p. 293-294), como:

[...] expressão da ação classista do capital contra uma classe trabalhadora que se encontra fragilizada [...] ela ocorre num quadro de excepcionalidade, em que as instituições da democracia representativa se encontram em crise [...] contesta o paradigma protetivo dos trabalhadores, desenvolvido em razão de sua condição de hipossuficiência, de modo a colocar em risco a feição ontológica do Direito do Trabalho.

Essas alterações desconsideram a condição vulnerável e subordinada do trabalhador, indo de encontro ao retrocesso do padrão de organização do trabalho que, por si só, já é devastador, trazendo o aumento da exploração e ampliando a precarização do trabalho (DRUCK, 2019).

Dentro dessa reforma é possível destacar alguns pontos que representam a total precarização e retirada de direitos da classe trabalhadora como a flexibilização da jornada e dos salários, além da negociação entre patrão e empregado, observando-se, claramente, a substituição da negociação sindical, ou seja, é a formalização das formas precárias de contratação de trabalho que beneficiam apenas o empresariado.

A precarização e a informalidade passaram a ser regra no mundo produtivo, e a terceirização se conforma como uma ferramenta propulsora para a acumulação flexível, através de subcontratações que diminuem o tempo de produção e de circulação do capital, ao mesmo tempo em que aumenta a exploração da força de trabalho (ANTUNES, 2018). 


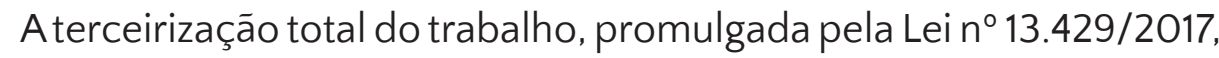
foi defendida como uma das formas de criar mais empregos e de modernização das relações de trabalho, porém, antes mesmo da aprovação da lei, este discurso já fazia parte do mundo empresarial e já havia pressão para a expansão da terceirização.

Segundo Druck (2016, p.37) no discurso empresarial “a terceirização tem sido defendida como símbolo maior da modernidade organizacional, expressão de um processo considerado 'natural' no capitalismo". Em as "101 Propostas para Modernização Trabalhista", publicada em 2012, a Confederação Nacional da Indústria (CNI) deixa claros os seus anseios:

Para promover a modernização trabalhista no Brasil, é preciso observar que modelo de relações do trabalho o país deseja para o futuro. Não é difícil encontrar convergências em torno da ideia de substituir o modelo atualmente em vigor por outro que privilegie a negociação, calcado na representatividade dos atores e capaz de se adequar às diferentes realidades e maximizar os ganhos para as empresas, os trabalhadores e o país. Um sistema trabalhista moderno é formado por uma base legal que trata dos direitos fundamentais e estabelece as regras do processo de diálogo entre as partes envolvidas, sendo o restante definido por negociações que levem em consideração especificidades setoriais, regionais e mesmo de cada empresa e de cada trabalhador. Nesse sentido, seria preciso substituir um modelo que quase tudo é definido em lei e muito pouco é negociado, por um outro que privilegie a negociação e reduza a tutela estatal homogênea. (CNI, 2012, p.18).

A legalização de todas as etapas de terceirização traz consigo a responsabilidade subsidiária no que refere aos direitos trabalhistas, onde a tomadora de serviço só é acionada caso a empresa terceirizada não arque com os direitos trabalhistas. Isso dificulta a reivindicação dos direitos pelos trabalhadores, pois não há contrato de trabaIho entre os mesmos e a empresa contratante do serviço. A presença 
de empresas interpostas entre o trabalhador e o tomador de serviço, no caso das relações de trabalho via terceirização, proporcionam o aprofundamento da subsunção do trabalhador ao capital, pelo fato de obscurecer sua percepção na participação do processo produtivo, além de dificultar a fiscalização do Estado em impor limites da exploração do trabalho, facilitando, por exemplo, relações de trabaIho análogas à escravidão (FILGUEIRAS, 2016).

\section{Contrarreforma e o binômio desregulação e flexibilidade do trabalho}

No Brasil, a reforma desrespeita os princípios constitucionais da dignidade humana e do valor social do trabalho, contrapondo-se àquilo que é da natureza dos direitos sociais: buscar fundar uma nação minimamente civilizada. Essas questões evidenciam a importância de um arcabouço jurídico que inclua as normas públicas de proteção ao trabaIho, com instituições públicas que fiscalizem e concretizem a sua aplicação e que contribuam para assegurar um patamar mínimo de direitos e colocar limites à ação predatória de um capitalismo sem travas.

A reforma introduzida por lei infraconstitucional, no caso em análise a Lei $n^{\circ} 13.467 / 2017$, bem como aquelas efetivadas em qualquer outro país, guardadas suas especificidades, histórias e sistemas jurídicos próprios, têm significado profundo ataque ao sistema de proteção social e às instituições públicas que atuam no mundo do trabalho, lócus desmercantilizador da produção das normas que regem as relações entre capital e trabalho. No caso do Brasil, essas instituições são: sistema federal de fiscalização, Ministério Público do Trabalho, Justiça do Trabalho e organizações sindicais dos trabalhadores.

Em Teixeira et al. (2017) e Véras (2018) foram analisadas as falácias dos argumentos utilizados pelos defensores da reforma em estudo. São falsas ideias sintetizadas nas seguintes afırmativas: 1) reduzir ou flexibilizar a tela de proteção social do trabalho é imprescindível para criar emprego, aumentar a competitividade e melhorar a produtividade; 2) a legislação é rígida e precisa ser modernizada (sabe-se que 
a CLT teve mais de 3/5 de suas disposições modificadas desde sua vigência em 1943. Aliás, além da legislação consolidada ter passado pelo crivo da Assembleia Nacional Constituinte, tendo sido incorporada e ampliada pela Constituição de 1988, o sistema brasileiro prioriza a negociação coletiva, assegurando o respeito a um patamar legal mínimo civilizatório).

Ademais, a flexibilidade é um componente estrutural do mercado de trabalho brasileiro, assentado na intensa rotatividade da mão de obra e na rapidez dos ajustes no nível de emprego, sendo o mercado de trabalho considerado a variável de ajuste em períodos de crise. Além disso, carrega traços estruturais de fragilidade, como uma economia de baixos salários e grande heterogeneidade estrutural, o que reforça a importância da regulação pública e das instituições aptas a fiscalizar e a concretizar sua aplicação (TEIXEIRA et al., 2017), assim como a falácia indecente de que salários baixos geram mais empregos.

As afırmativas de defesa da reforma não resistem a qualquer análise diante do desempenho da economia brasileira em período recente (governos do PT), não obstante a adoção de composições/coalizações e a política baseada fortemente no consumo interno e na desoneração fiscal, em que, com a mesma tela dos direitos acusados de responsáveis pelo desemprego, houve crescimento econômico, elevação da renda do trabalhador, formalização dos contratos de emprego e baixas taxas de desemprego (ainda que a alta taxa de precarização também fosse um componente presente). Por derradeiro, lembramos também a falácia da invocada insegurança jurídica.

Do ponto de vista dos trabalhadores terceirizados, as consequências dessa situação vão muito além da mera precarização das garantias do trabalho, significando mesmo uma forma de precarização da sua própria condição humana, vez que são desalojados do contexto da unidade em que prestam serviços. Os terceirizados, assim, tornam-se objetos de contratos e transformam-se em seres invisíveis. E isso não é mera figura de retórica, pois a maior forma de alguém ver reduzida a 
sua condição de cidadão é lhe retirar a possibilidade concreta de lutar pelo seu direito e é isso, exatamente, o que faz a terceirização, nos moldes ideais do projeto neoliberal para um mercado livre e soberano, visando manter a força de trabalho a custos muito baixos.

A desregulação, por sua vez, é a retirada, do âmbito da legislação, de parte dos direitos dos trabalhadores, de modo a permitir que eles sejam regulamentados através de negociações coletivas entre as categorias envolvidas. O artigo 444 da CLT admite a contratualidade plena do conteúdo das relações de trabalho, "em tudo quanto não contravenha às disposições da proteção ao trabalho, aos contratos coletivos que lhes sejam aplicáveis e às decisões das autoridades competentes" (BRASIL, 1943).

Entretanto, no atual panorama, no Brasil, desenvolve-se a fraqueza dos entes sindicais frente à robustez do capital dominante, que desvirtua, por completo, a finalidade das negociações coletivas, na medida em que não há paridade entre os negociantes.

No tocante à flexibilização, de acordo com Catharino (1997), é a capacidade de adaptação do regime normativo e das instituições à vontade unilateral ou bilateral das partes da relação de trabalho; diferentemente da desregulação, esse fenômeno implica nova regulamentação das relações de trabalho, de modo a compatibilizá-las com os interesses da classe dominante no modelo neoliberal, qual seja: aquela que detém o capital. No Brasil, os principais retratos da flexibilização das normas trabalhistas dizem respeito ao aumento do poder dos empregadores no tocante às formas de contratação, às jornadas de trabalho e à política salarial. Ou seja, a flexibilização, para os trabaIhadores, leva à desregulamentação de direitos.

Compreende-se que o resultado desse processo é que o capital estrangeiro, que sempre esteve presente na produção de bens e serviços no Brasil, hoje não encontra quase nenhuma barreira para atuar na esfera da produção, da extração de minerais e na circulação de mercadorias e capitais. A única restrição que ainda persiste, que lhe impede plena de- 
senvoltura, é a vedação para compra de terras, mas existe projeto que altera a legislação ${ }^{16}$. Entretanto, se a plena liberdade do grande capital atuar no país tinha sido garantida na esfera da produção e da circulação, havia ainda um mercado que não tinha se adequado às normas de reprodução do capitalismo globalizado e financeirizado: era o mercado de trabalho e, portanto, tratava-se da gestão da força de trabalho. A legislação, nesse campo, plasmada na CLT, passou a ser vista, e de maneira cada vez mais intensa, como um obstáculo maior ao desenvolvimento do capitalismo integrado ao mercado internacional.

Nesse contexto, assume importância ímpar a reforma trabalhista promovida pelo governo Temer e a reforma da previdência promulgada no governo Bolsonaro.

O projeto defendido pelo capital financeiro para o Brasil é formado de três objetivos básicos: desnacionalizar o que ainda há de nacional no país, particularmente a terra, o que resta das estatais, a plena exploração do petróleo, mas também setores de atividades, num processo de desnacionalização que vem ganhando fôlego desde os anos 1990; diminuir o tamanho do Estado para algo em torno de 10\% do Produto Interno Bruto (PIB), para o qual a Emenda Constitucional 95/2016"7, cujo projeto ficou conhecido como PEC da Morte, pois congela investimentos públicos por 20 anos em áreas essenciais como saúde e educação; e por fım, flexibilizar totalmente o mercado de trabalho brasileiro. Isto é, em consonância com a nova ordem mundial conformada pelo capitalismo financeiro, que modifica o papel do Estado no tocante à regulação de vários aspectos da vida social e econômica, o Brasil do governo Temer aprovou uma reforma radical que altera significativamente a relação capital/trabalho.

Não atrás em postura de agudização da barbárie está o governo de Bolsonaro, retirando, de um contexto já demarcado por congelamento, aquilo que já se tinha em pleno déficit e precariedade, como verbas para a educação e autorização para devastação de terras antes sob reserva e proteção. 
Podem-se vislumbrar, com as medidas tomadas, conceitos legitimados de precarização do trabalho, como: abrangência aumentada na esfera da terceirização, barateamento de salários, pejotização ${ }^{18} \mathrm{e}$ cooperativismo; perda de identidade coletiva com o desmonte da representatividade dos trabalhadores e a regressão das garantias de seus direitos, rotatividade, flexibilidade da jornada de trabalho e/ou funcional, restrição à promoção, formação de carreira, não afetação das vantagens decorrentes da convenção coletiva da atividade, quarteirização (a terceirizada pode subcontratar), heterogeneidade e segmentação (VÉRAS, 2018).

Cabe destacar que, considerando o contexto geral da reforma, subentende-se o fato de que a Justiça do Trabalho possa ter praticamente perdido sua função, posto que tudo que decorre da relação capital/ trabalho é passivel de ser negociado entre o trabalhador e o empregador, com exceção de situações que atentem contra a vida e a saúde do trabalhador e o pagamento inferior ao salário mínimo, o que ainda é garantido pela Constituição de 1988. Isso resulta da instituição do negociado sobre o legislado, contrariando todo o ordenamento jurídico formado e, ainda, atingindo cláusulas pétreas de modo reflexivo, onde se observa que o salário pode ser inferior ao piso (seja ele definido para uma categoria ou para uma empresa, com base em um acordo coletivo), desde que o trabalhador assim concorde.

Parece simples compreender que a negociação entre o patrão e o trabalhador individual nunca ocorre em condições de igualdade, estando este último sujeito a fazer acordos que lhe são desfavoráveis. A partir desse preceito, deixa-se de reconhecer que a relação entre o empregador e o trabalhador (quando isolado) é desigual, posto que o trabalhador é completamente dependente de seu emprego.

A desigualdade de condição entre o trabalhador e o empregador, no momento da negociação, é fato inconteste e é por isso que, no mundo todo, foram criados mecanismos de defesa do trabalhador. Vendo por outro ângulo, o acordado sobre o legislado se desdobra no fato de, ao 
contrário do que decorria da Justiça do Trabalho, o trabalhador pode, agora, abrir mão de qualquer direito, de forma que não há possibilidade de, no futuro, ele entrar na justiça e seu pleito se transformar em um passivo trabalhista. O resultado da aplicação dessa regra é que as empresas podem adotar um conjunto de possibilidades de contrato, a depender de seu interesse. No lugar de regras rígidas, decorrentes da aplicação das leis e do resultado da negociação com o sindicato, vemos a flexibilização completa da força de trabalho (BIAVASCHI, 2016).

Tal postura corrobora o enfraquecimento do sindicato, o que, consoante à reforma, está no fato de que durante os anos 1980 a forte presença sindical no chão de fábrica garantia um poder de barganha importante aos representantes sindicais de categorias de trabalhadores brasileiros (STAMPA, 2012).

Outro aspecto da reforma que é muito importante destacar é que a terceirização pode ocorrer para qualquer atividade do setor privado e quase todas do setor público, seja ela meio e/ou fim. No caso específico da nova abrangência no setor público, essa mudança vem ao encontro do objetivo de reduzir o Estado.

No que concerne ao que já é efetivo e reflete mudanças, vale frisar a reforma da Previdência, que também vai ao encontro da reforma trabalhista, permitindo redução de atividades típicas do Estado e, sobretudo, uma maior atuação do segmento privado na previdência complementar. São medidas abrangentes e radicais que alterarão signifıcativamente a proteção social do risco, velhice e morte.

Por fim, cabe destacar dados da força de trabalho terceirizada no Brasil, os quais apontam para múltiplas formas de precarização do trabalho (ANTUNES; DRUCK, 2015), indicando que os trabalhadores terceirizados podem estar mais expostos a esta. A terceirização, portanto, manifesta-se como uma das mais visíveis expressões do processo de precarização social do trabalho (FRANCO; DRUCK, 2007), possuindo traços particulares no que se refere aos países de economia periférica, como é o caso do Brasil. 
O fato do Brasil se localizar na periferia do capitalismo faz com que o processo de acumulação ocorra de forma mais acentuada no que concerne aos mecanismos de precarização social, que são mais intensos. Nesse contexto, aumenta o número de trabalhadores sem vínculos empregatícios formais, os chamados autônomos, e hoje podemos também vê-los denominados como Microempreendedores Individuais (MEI). Além disso, há uma redução dos postos de trabalho com melhor remuneração. A precarização do trabalho no capitalismo se caracteriza pela constituição de uma nova precariedade salarial, que seria o "modo de organização laboral baseada na lógica do trabalho flexível” (ALVES, 2017, p. 89).

Desse modo, a precarização é um elemento estrutural do trabalho que incide sobre os trabalhadores que estão inseridos em espaços já precarizados e passam a ser submetidos cada vez mais a mudanças na organização e gestão do trabalho, precisando se adaptar às novas demandas do capital, mesmo quando já estão submetidos a uma forte exploração da sua força de trabalho.

\section{Conclusão}

No Brasil, os retrocessos, em diversos âmbitos da sociedade, sobretudo entre 2016 e 2020, revelam uma agenda de desmonte de direitos e precarização massiva do trabalho, em consonância com uma pauta governamental que parece ultrapassar até mesmo os moldes neoliberais já conhecidos pelo país, pois os interesses privados e aliados ao capitalismo não demonstram ter limites ou possíveis impedimentos. Os trabalhadores terceirizados possuem salários menores, maior carga horária de trabalho e se encontram em uma situação caracterizada por um número expressivo de acidentes de trabalho e, frequentemente, de menosprezo aos direitos trabalhistas. A terceirização também carrega a condição de fragmentar as ações coletivas, já que, nessa modalidade de trabalho, há um incentivo à individualização das relações de trabalho e ao aumento da competitividade. 
Em meio a esse quadro de desregulamentação das relações trabalhistas, no qual ocorre uma crescente necessidade de expansão da lógica capitalista, e há também fortes tentativas de cooptação dos trabalhadores, a fim de que incorporem ideologicamente a racionalidade do capital, e, por isso mesmo, é que a Lei da Terceirização é anunciada como uma lei que regulamenta os trabalhadores terceirizados para que tenham acesso aos seus direitos como qualquer outro trabalhador.

A terceirização no Brasil não é traço meramente contingencial por conta da lei ou inescrupulosidade de maus capitalistas. Ela é um traço orgânico do capitalismo brasileiro. É um modo de reafirmar a forma de ser de identificação do capitalismo brasileiro baseado na superexploração da força de trabalho (exploração da força de trabalho que articula intensificação do trabalho, alongamento da jornada laboral e rebaixamento salarial num país de capitalismo periférico).

Os retrocessos advindos com as reformas trabalhista e da previdência, conjugadas com a lei da terceirizarão, revelam uma agenda de desmonte de direitos e precarização massiva do trabalho no Brasil, onde também tem lugar uma crescente insegurança jurídica para os trabalhadores.

Urge, pois, a regulamentação correta da gestão do trabalho, que impeça a sua utilização predatória e permita isonomia de direitos entre trabalhadores e livre escolha de participação e representação sindical para sua organização coletiva e defesa de seus direitos.

\section{Referências}

ALVES, Giovanni. A nova precariedade salarial. In: NAVARRO, Vera Lucia; LOURENÇO, Edvânia Ângela de Souza (Org.). O avesso do trabalho IV. São Paulo: Outras expressões, 2017.

ANTUNES, Ricardo. O privilégio da servidão: o novo proletariado de serviços na era digital. São Paulo: Boitempo, 2018.

ANTUNES, Ricardo; DRUCK, Graça. A terceirização sem limites: a precarização do trabalho como regra. O Social em Questão, Rio de Janeiro, v. 34, n. 1, 2015. 
ANTUNES, Ricardo; FILGUEIRAS, Vitor. Plataformas digitais, Uberização do trabalho e regulação no Capitalismo contemporâneo. Contracampo, Niterói, v. 39, n. 1, p. 27-43, abr./jul. 2020.

BEHRING, Elaine R. Brasil em contrarreforma. São Paulo: Cortez, 2003.

BIAVASCHI, Magda Barros. O processo de construção e desconstrução da tela de proteção social do trabalho: tempos de regresso. Estudos Avançados, São Paulo, v. 30, n. 87, p. 75-87, maio/ago. 2016.

CARCANHOLO, Marcelo. Dialética do desenvolvimento periférico. Anais... Colóquio Latino-americano de Economistas Políticos. São Paulo, 31 out. a 2 nov. de 2004.

CATHARINO, José Martins. Neoliberalismo e sequela. São Paulo: LTr, 1997.

CONFEDERAÇÃO NACIONAL DA INDÚSTRIA (CNI). 101 propostas para modernização trabalhista. Emerson Casali (Coord.). Brasília: CNI, 2012.

DAL ROSSO, Sadi. O ardil da flexibilidade. São Paulo: Boitempo, 2017.

DRUCK, Graça. A indissociabilidade entre precarização social do trabalho e terceirização. In: TEIXEIRA, Marilane Oliveira; RODRICUES, Helio; COELHO, Elaine d'Ávila (Org.). Precarização e terceirização. São Paulo: Sindicato dos Químicos-SP, 2016.

DRUCK, Graça; DUTRA, Renata; SILVA, Selma Cristina. A contrarreforma neoliberal e a terceirização: a precarização como regra. Cadernos $C R H$, Salvador, v. 32, n. 86, p. 289-306, ago. 2019.

FILGUEIRAS, Victor Araújo. Terceirização e trabalho análogo ao escravo: estreita relação na ofensiva do capital. In: TEIXEIRA, Marilane Oliveira; RODRIGUES, Helio; COELHO, Elaine d'Ávila (Org.). Precarização e terceirização. São Paulo: Sindicato dos Químicos-SP, 2016.

FRANCO, Tânia; DRUCK, Graça (Org.). A perda da razão social do trabalho. São Paulo: Boitempo, 2007.

GALEANO, Eduardo. As veias abertas da América Latina. Rio de Janeiro. Paz e Terra. 1981.

GIMENEZ, Denis Maracci; KREIN, José Dari. Terceirização e o desorganizado mercado de trabalho brasileiro. In: TEIXEIRA, Marilane Oliveira; RODRICUES, Helio; COELHO, Elaine d'Ávila (Org.). Precarização e terceirização. São Paulo: Sindicato dos Químicos-SP, 2016. p. 17-33. 
HARVEY, David. 17 contradições e fim do capitalismo. São Paulo: Boitempo. 2016. JORDÃO, Ana Paula Ferreira; STAMPA, Inez. Precarização e informalidade no "mundo do trabalho" no Brasil: notas para reflexão. Anais... VII Jornada Internacional de Políticas Públicas. São Luiz/MA: UFMA, 2015.

MARCELINO, Paula; CAVALCANTE, Sávio. Por uma definição de terceirização. Caderno CRH, Salvador, v. 25, n. 65, p. 331-346, maio/ago. 2012.

MARINI, Ruy Mauro. Dialética da Dependência. In: TRASPADINI, Roberta; STEDILE, João Pedro (Org.) Ruy Mauro Marini: vida e obra. São Paulo: Expressão Popular, 2011.

MARX, Karl. Processo de trabalho e processo de valorização. In ANTUNES, Ricardo. A dialética do trabalho: escritos de Marx e Engels. São Paulo: Expressão Popular, 2004.

STAMPA, Inez. Transformações recentes no "mundo do trabalho" e suas consequências para os trabalhadores brasileiros e suas organizações. Revista Em Pauta. Rio de Janeiro, 2012, v.30, n.10.

TEIXEIRA, Marilane Oliveira. et al. Contribuição crítica à Reforma Trabalhista. Campinas: GT Reforma Trabalhista Cesit/IE/Unicamp, 2017.

VÉRAS, Roberto. Brazilian Labour Reform in historical perspective. Clobal Labour Journal, v. 9, n.3, p. 319-338, 2018.

\section{Notas}

1 Advogada. Mestre e doutoranda em Serviço Social pela Pontifícia Universidade Católica do Rio de Janeiro (PUC-Rio). Pesquisadora do Crupo de Pesquisa Trabalho, Políticas Públicas e Serviço Social (TRAPPUS), cadastrado no DCP/CNPq Brasil. ORCID iD: https://orcid.org/0000-0002-7997-6940. elisabethbarauna@ hotmail.com.

2 Mestre e doutoranda em Serviço Social pela Pontifícia Universidade Católica do Rio de Janeiro (PUC-Rio). Pesquisadora do Grupo de Pesquisa Trabalho, Políticas Públicas e Serviço Social (TRAPPUS), cadastrado no DCP/CNPq. Brasil. ORCID iD: https://orcid.org/0000-0002-4543-5185. lourrensse@gamil.com.

3 Doutora em Serviço Social. Professora do Departamento de Serviço Social da Pontifícia Universidade Católica do Rio de Janeiro (PUC-Rio). Pesquisadora do Grupo de Pesquisa Trabalho, Políticas Públicas e Serviço Social (TRAPPUS), cadastrado no DCP/CNPq. Brasil. ORCID iD: https://orcid.org/0000-0003-29913594. analole@gmail.com. 
4 Doutora em Serviço Social. Professora do Departamento de Serviço Social da Pontifícia Universidade Católica do Rio de Janeiro (PUC-Rio). Coordenadora do Grupo de Pesquisa Trabalho, Políticas Públicas e Serviço Social (TRAPPUS), cadastrado no DGP/CNPq Brasil. Bolsista de Produtividade em Pesquisa do CNPq. ORCID iD: https://orcid.org/0000-0003-3770-1129. inezstampa@gmail.com.

5 O período foi selecionado pelo corte do golpe de Estado de 2016, o qual destituiu, sem presença de provas, a presidente eleita, através de estratégias jurídico-midiáticas-parlamentares em associação com as elites do país. A prática do golpe de Estado legal (ou pseudolegal, constitucional, institucional, parlamentar, dentre outros termos) parece ser a nova estratégia das oligarquias latino-americanas. Ocorreu também em Honduras (2009) e no Paraguai (2012), países que a imprensa costuma chamar de "República das Bananas". A estratégia se mostrou eficaz e lucrativa para eliminar presidentes (muito moderadamente) de esquerda. Consolidou-se, no Brasil, em 2016. Desde então o país tem sofrido diuturnamente com o aprofundamento da agenda neoliberal, radicalizada no governo Bolsonaro.

6 Lei $n^{\circ}$ 13.429, de 31 de março de 2017. Altera dispositivos da Lei $n^{\circ} 6.019$, de 3 de janeiro de 1974, que dispõe sobre o trabalho temporário nas empresas urbanas e dá outras providências; e dispõe sobre as relações de trabalho na empresa de prestação de serviços a terceiros.

7 Flexibilização é aqui utilizada para expressar a verdadeira desregulamentação que as reformas trabalhistas vêm ocasionando em desfavor dos trabalhadores. O termo é muito utilizado na literatura sobre o tema e está associado ao pensamento neoliberal, o qual impõe a ideia que quanto mais livres forem as relações de consumo e de trabalho, maior será o crescimento da economia.

8 De acordo com Gimenez e Krein (2016, p.18): “Diferentemente dos países centrais, no Brasil não chegou a se constituir uma sociedade organizada a partir do trabalho assalariado, que inclui a construção de direitos e proteção social para o conjunto dos trabalhadores. Portanto, a desorganização é uma característica estrutural do mercado de trabalho brasileiro, que se manifesta no baixo índice de assalariamento, na informalidade, na elevada rotatividade, na abertura do leque salarial e na forte desigualdade social, inclusive entre os rendimentos do trabalho".

9 Uberização vem da referência à empresa multinacional Uber - plataforma que conecta usuários a motoristas parceiros, prestando serviços via aplicativo na área do transporte privado urbano, através de uma plataforma digital de transporte que permite a busca por motoristas baseada na localização do consumidor.

10 Lei de $n^{\circ} 13.467$, de 13 de julho de 2017. Altera a CLT, aprovada pelo Decreto-Lei $n^{\circ}$ 5.452, de $1^{\circ}$ de maio de 1943, e as Leis n.os 6.019, de 3 de janeiro de 1974, 8.036, de 11 de maio de 1990, e 8.212, de 24 de julho de 1991, a fim de adequar a legislação às novas relações de trabalho. 
11 Emenda Constitucional $n^{\circ} 103$, de 12 de novembro de 2019. Altera o sistema de previdência social e estabelece regras de transição e disposições transitórias.

12 Instrução Normativa TST n 41, de 21/06/2018. Dispõe sobre a aplicação das normas processuais da CLT alteradas pela Lei $n^{\circ} 13.467 / 2017$.

13 Instrução Normativa $n^{\circ}$ 41/2018 do TST, que explicita normas de direito processual relativas à Lei $n^{\circ} 13.467 / 2017$.

14 Súmula n 331 do TST. Contrato de Prestação de Serviços. Legalidade - Res. 174/2011, DEJT divulgado em 27, 30 e 31.05.2011.

15 Projeto de Lei $n^{\circ} 4.330$, de 2004. Dispõe sobre o contrato de prestação de serviço a terceiros e as relações de trabalho dele decorrentes.

16 Trata-se do Projeto de Lei n².963/2019, que regulamenta o artigo 190 da Constituição Federal. Foi batizado de "Terra para + Empregos + Alimentos". Além da venda, a proposta também regulamenta o arrendamento de propriedades rurais brasileiras por pessoas físicas e jurídicas de outros países.

17 Altera o Ato das Disposições Constitucionais Transitórias, para instituir o Novo Regime Fiscal, e dá outras providências.

18 O termo pejotização consiste na forma de contrato de trabalhadores (pessoas físicas) por meio da constituição de pessoa jurídica para prestar serviços, camuflando a relação de emprego especialmente pela presença da subordinação, com a finalidade singular de afastar o dever de pagamento das verbas e dos encargos trabalhistas e previdenciários, conduta que, apesar de comum, continua sendo considerada ilegal. 